\title{
Between Truth, Legitimacy, and Legality in the Post-truth
}

\section{Era}

\section{Anna Maria Lorusso ${ }^{1}$ (D)}

Published online: 22 July 2020

(c) The Author(s) 2020

\begin{abstract}
The post-truth regime is a regime in which certain central categories of modernity seem to be inadequate: that of truth as correspondence, that of truth as verification, and that of truth as sincerity. This reflection aims at proposing a shift from the category of truth to the category of legitimacy, in order to rethink (replace?) those of correctness, objectivity, adequacy. The advantage potentially offered by the concept of legitimacy, with regards to that of truth, has to do with the reference to a given context (wherein truth tends to be a universal ideal), with an element of social recognition (wherein truth does not depend on recognition; it is valid per se) and a processual dimension (wherein truth does not become truthful), which makes the management of discourses more flexible, without abdicating to their deregulation.
\end{abstract}

Keywords Post-truth $\cdot$ Discursive regime $\cdot$ Semiotics $\cdot$ Interpretation

\section{The Contours of the Problem}

Over the following pages, I will outline several perspectives on what I call the posttruth era, or post-truth infosphere (using the term coined by Luciano Floridi [1]) - a cultural situation that I see as dominated by a regime of digital truth, and in which I can see that certain central categories of Modernity seem to be lacking: truth as correspondence, truth as verification, and truth as sincerity.

Obviously, I use the term "regime" in the Foucauldian sense, one I consider particularly pertinent here. Digital tools today are not just media that merely allow us

Anna Maria Lorusso

annamaria.lorusso@unibo.it

1 Department of Philosophy and Communication, University of Bologna, Bologna, Italy 
to transmit content. Although the traditional media (TV and radio) were never particularly neutral, there is no doubt that the intertwining of the digital sphere with the "material"1 one is absolute, and that together they contribute to the creation of a real sphere with its own logic, its own criteria for legitimation, its own standards, and its own rules. The rules governing the management of this sphere define the limits and systems of power, but also the limits and systems of truth. According to Foucault, truth and power must be inter-defined. It is insufficient to frame the problem of post-truth (as often happens today) merely as a problem of communication, of mediatic poisoning. The problem is deep, and it has to do with the criterion of truth and where the authorization to set these criteria comes from.

Foucault introduces the concept of 'regime of truth' in Discipline and Punish [2], but the most interesting text on this subject is the interview The Political Function of the Intellectual (1976), in which Foucault argues, in contrast to a certain philosophical myth, that truth "is produced by virtue of multiple constraints and it induces regulated effects of power". This points that "each society has its regime of truth":

1. "The types of discourse [society] harbors and causes to function as true";

2. "The mechanisms and instances which enable one to distinguish true from false statements" and

3. "The way in which each is sanctioned";

4. "The techniques and procedures which are valorized for obtaining truth";

5. "The status of those who are charged with saying what counts as true". [3].

According to this frame, "truth" is "a system of ordered procedures for the production, regulation, distribution, circulation and functioning of statements"; it is linked "by a circular relation to systems of power which produce and sustain it, and to effects of power which it induces and which redirect it".

My impression is that, today, all these aspects we have mentioned are living a specificity (consider how our society makes discourses which are nothing more than rumors function as truth, how lies in the scientific field are sanctioned as plausible, how certain techniques and procedures, such as those related to big data, are valorized as truthful, etc.), and that this set of specificities makes the expression "posttruth" relevant as something new, a regime specific to our time.

I do not consider post-truth to be synonymous with 'fake news', nor do I suggest that it is just a neologism to express an old concept, with public lies having always been a reality. Rather, I believe post-truth is worthy of attention because it is a specific regime of truth, in which the "digital" component is fundamental, not because the post-truth is originated by digital media, ${ }^{2}$ but because it is sustained, nourished and maintained by digital media.

\footnotetext{
1 "Material" can be an equivocal term, but I mean something that has to do with our experience, our senses, our body, the world of objects we interact with. In my mind there is currently no better word with which to do this than "material".

2 In one of my previous works [4] I have outlined how, in genealogical terms, we can trace the post-truth phenomenon back to developments in television that take place from the $1980 \mathrm{~s}$ onwards.
} 
In my attempt to define some features of this regime, I will start by highlighting that which is no longer valid within it; those epistemological categories that are no longer useful for understanding the post-truth era.

Following this initial criticism, I will attempt to say something more proactive and constructive regarding the criteria I hold to be central to this new regime, and I will support the thesis that the criterion of truth should be replaced with the more effectively criterion of legitimacy.

Finally, I will focus on the interpretative dimension that legitimacy presupposes, giving the interpreter a much more strategic role than in the "old" truthbased paradigm.

\section{Some Old Ideas About Truth}

Some central categories of modernity in the digital post-truth regime seem to me to be overwhelmed, radically outdated: namely those of truth as correspondence, truth as verification, and truth as sincerity.

I do not wish here to summarize a debate on truth that has seen a thousand studies and two millennia of reflection. I just want to highlight the aspects of these categories that make them inadequate for getting to grips with what is happening today in terms of 'post-truth'.

(1) The idea of correspondence entails a dimension of accessible and observable factuality that raises a number of problems, both pragmatic and theoretical.

I will begin with the theoretical.

I do not question that a "level of reality" exists—a level where things always work in? a certain way.

I do think, however, that when we observe this level of reality, even when simply conceptualizing and then expressing it, we make use of semiotic mediations. This idea is strongly semiotic, and perhaps the most important voice in this regard is that of C.S. Peirce [5]. Despite being a realist, Peirce placed the idea of interpretative mediation at the base of his semiotics and his philosophy of language. He recognizes that, upstream of any semiotic practice (whether it was the most simple statement or the most complex interpretative practice), there is a "reality datum" which he calls the Dynamic Object: the real as it is. He asserts, however, that as soon as this level of reality enters the semiotic circuit, as soon as it must therefore be expressed, said, shared, it is transformed into something that he calls an Immediate Object, a version of the Object that is accessible and ready to enter the circuit of semiosis: to be made pertinent in a particular way, to create certain interpretative effects and rules of action. Some of the interpretative effects produced by each sign will take on a certain stability and become shared (by one or more people), causing it to "return" to the level of reality, and, as such, constituting new realities. In this way, factuality will be inescapable, though always mediated by interpretation. 
From this point of view, I am radically Peircian. Even if there is a level of dynamic objects, of "pure" reality, of Primacy?, we perceive it through mediations that are not "objective". This perspective does not mean make us radical relativists. There is no subjectivism in all this; the interpretations that "count" in modifying the real are not individual. Peirce wants to highlight, however, that all reality is mediated by categories, conceptualizations, shared structures that immediately come into play when we are dealing with reality, for which the "pure real" is merely postulated.

Instead, it means, perhaps, more than anything else, to be conceptual relativists, as Diego

Marconi says in his study on truth [6], in order to differentiate between radical and genuine relativism, epistemic relativism, and so on. We identify how things are thanks to particular concepts, those by which we identify and categorize the constituents of reality.

It is why the assertion that salt is sodium chloride is true according to the conceptual scheme of chemistry, while it is not true according to the conceptual scheme of the philosophy of nature of the Renaissance. Chemistry and Renaissance philosophy are not sceptical or relativist forms of thought; they just act according to different conceptual categories, and this pushes them to perceive and postulate a different kind of reality. Interpretations of the world seem to come after the pure reality but the "pure reality" to which we refer is already mediated by our schema.

If we are conceptual relativists (I would prefer to say semiotic relativist, because the category of "concept" is perhaps too cognitive for my approach, as we also have to take into account language, somatic mediations, and so on), it is difficult to think of the truth in terms of correspondence because each statement should be led back to its "paradigm", to the cultural system in which it exists. For example, my beliefs regarding vaccines will not be comparable with those of someone who grew up in a completely different culture, an Aboriginal culture for example, where animism is strong. And this is also true for the "small facts" with which we are confronted in our everyday life, where it seems to each of us that there is not a problem of paradigm because our "neighbours" share the same ones. To recognize (even in our solitary thoughts) that we are immersed in the fog or surrounded by smog generates a chain of very different interpretative thoughts and effects. Before we embark on any discourse about this, our Immediate Object—fog/smog — despite being the same set of water particles and therefore the same Dynamic Object, is different.

Moreover, this brings us to the empirical problem I mentioned earlier. I believe that in today's infosphere there is a sizeable and specific problem of accessibility, which also arises with respect to "small facts". To summarize the problem: we have widespread accessibility. Everything is accessible to so many people and in such a short temporal lapse that it becomes hard to relate to something "original". Information, reality, have always been already accessed by many people before us, that means that they have already been reworded, reframed, relaunched, repeated. Thus, again, I say: even if a "pure" reality level of facts exists somewhere (the Peirce's Dynamic Object), this "factuality" immediately 
becomes the object of multi-layered discourses, always already said, already framed.

For me, as a semiotician, this generalized accessibility that makes everything hyper-mediated shifts the focus of attention. The most interesting aspect of what happens today, even when faced with a "very simple" descriptive statement (i.e., "there was an accident along my route an hour ago"), is not to verify whether the statement corresponds to an event that actually happened, but to ascertain whether or not to trust it, because the levels of mediation and distancing from reality have multiplied: who made the statement? Which source does this information come from (Is it Google Maps providing me with traffic updates or a friend who lives there)? Why is someone telling me this, where is the interest?

Obviously, we could say that all these questions have something to do, in some way, with the correspondence of the statements to facts, but the point refers more to the "nature" of the sentence, its reason, its origin, its truthfulness. And truthfulness is a weaker notion than truth [7]; it is something that has to do with accuracy, honesty, credibility - subjective components of interpretative accounts that chase each other very quickly through our post-truth era until they overlap.

I believe that this "extreme" accessibility is a noteworthy communicative feature of our time. The rapidity of the diffusion of news, the viral nature of comments, the rhetorical structure of sharing (i.e., retweeting) today builds a stratification much faster than in the past, and the presumed initial nucleus of the Dynamic Object is very quickly lost, leaving the infosphere nothing but? radically stratified units of information.

Judging the truth of these pieces of information using particular correspondence criteria is simply inadequate, empirically impossible and, I would add, rather uninteresting because the interesting part is precisely the stratification (or mediation) that immediately shapes the initial information data.

Indeed, it is within these layers that the judgment of truth becomes complex, and we shift from truth (a matter of presumptive objectivity) to truthfulness (a matter of negotiable interpretation): the many versions of the facts progressively multiply and all we can do is retrace their paths of formation (as well as the reasons for these paths and the empirical elements they involve), but we cannot verify their "correspondence" to reality. Reality is in and through those interpretative layers.

(2) In light of this acceleration and over-production of the infosphere, the idea of verification and proof (which I have mentioned before) also seems to lose its place on any genuine path of discovery, abdicating to the dynamics of selfconfirmation that digital bubbles and echo chambers feed on.

Verification today seems neither a matter of correspondence nor one of genuine argumentative assessment, genuine comparison or in-depth procedures. I am not generically stating that people today are superficial. I'm saying that today the information world works in a way that systematically discourages genuine forms of verification. 
It is a well-studied phenomenon ${ }^{3}$ : the more complex the informative world becomes, the more we tend to live in information bubbles. It is not a psychological phenomenon, but something set by the algorithms that select our way of living online. On the one hand, there are the social networks, in which each individual tends to build a network of "friends" or similar contacts (I can be in a network that does not put old friends back in contact, but those who support a given political party or football team, or those that like cooking, or vegan food, and so on). On the other hand, there is the Internet, with its search algorithms, its distributors (from Amazon to Netflix) where each user is profiled, and thus receives information and stimuli shaped by their preferences. The result is that a kind of familiar micro-world is structured around each one of us, a microworld that filters and leaves out everything that is foreign. We are in contact (without any real face-to-face interaction) with thousands of people who share our same tastes and opinions, and we receive thousands of suggestions and handpicked information selected so perfectly for us that we feel no need to expand the boundaries of our world. Our world already seems big, too full of information and people; and it does not matter if that information and those people are modeled on us.

In these bubbles of shared tastes and opinions it is difficult to build authentic argumentative paths, because confirmation mechanisms are strengthened. All the typical elements of a genuine discovery path (a surprising fact, a different point of view, a different premise) are minimized, whilst the most recurrent rhetorical pathways seem to be paralogisms, tautologies, generalizations: discursive moves which give only the impression of an argumentative progress. In these bubbles where confirmation bias dominates, facts are almost always reinforced facts, convincing facts for all, beyond question, according to an absolutizing mechanism that ends up giving weight, giving reality to discursive stratifications that are independent of any real assessment. How much has fake news become real? How can it happen that a lie like "Obama was born in Africa" became a term of reference for many people sceptical about his legitimacy? Here we touch upon another problem which has to do with the formation of impermeable bubbles and trivialism: the absence of any stable and shared criterion of hierarchization of knowledge. This problem also undermines the possibility of a genuine argumentative mechanism: the premises of reasoning should be justified, but by whom? Who is the "guarantor" of these premises? There is no single institution, no special body. How can we discriminate from right and wrong premises? These questions open us up to the enormous problem of authorities of knowledge, but that is a matter for another paper.

(3) This problem brings me to the third "classical approach" to truth that today seems, to my mind, to be entirely inadequate: the idea of sincerity. It should be a basic pragmatic and ethical rule of communication, as theorized by Grice in his conversational maxims [9]: "be truthful” says his maxim of Quality, do not

\footnotetext{
3 The main reference for the problem of information bubbles, or filter bubbles, in post-truth era is the book by Pariser [8].
} 
say what you believe to be false and do not say something for which you lack adequate evidence. But this maxim seems to be less and less relevant (and, in any case, of little use on an epistemic level). Not only it is disregarded in fact, but it is no longer even a criterion, and this is the interesting (and worrying) point about the post-truth regime (and one of the reasons why it is important to speak in terms of the regime: the rules and the criteria relevant for establishing what is true).

The discursive functioning of the contemporary infosphere requires a continuous intervention (as the book by Floridi already mentioned in [1] underlines), we seem to no longer have the right to not react, and any lack of adequate evidence (as mentioned before) cannot be an obstacle to this continual solicitation; we must go further. In this way, the kind of sincerity criterion that arises is an emotional not a cognitive one. Sincere today means to be sympathetic to someone, not to be honest about reality. Moreover, there is generally a great deal of confusion surrounding the concept of sincerity: sometimes intentionally tendentious information is circulating that is clearly contrary to the principle of sincerity, other times it is information that is simply unverified. "Fake" does not always mean "not sincere"; it may mean wrong, unverified, misinterpreted. Furthermore, jurists are faced with a complex series of problems in this regard. In their situation, a typology of falsifications with different objectives (distinguishing between the phenomenon of fake news and hate speech) is at play, one that decides (even before the event) whether the fake is to be placed in the bedrock of the "juridically illicit" or whether it assumes criminal relevance insofar as, for example, it provokes social alarm or damages public order. The question is whether the protection of freedom of information or the rights of the person (honour, reputation, personal identity, dignity) should prevail in the conflict with the right to information. Ultimately, the question is whether it is legally possible to regulate a form of filtering or sanction that is not censorship.

Faced with all this (the multiplication of versions of reality, the solicitation to react immediately with disregard to evidence, the dominance of a sympathetic criterion, etc.), which implies a confusion at the level of truth and a multiplication of claims to truth, it is nevertheless amazing to see the emergence of a sort of need for objectivity, as if, aware that the discursive arena of the infosphere is in the hands of an uncontrollable thrust, we need to find somewhere outside these discourses, a free port, an area of objectivity. This free port seems to lie in statistics and big data. Here, we find a form of impersonal objectivity that acts almost as a compensation for the radical individualization of discourses: statistical forms, algorithms, and diagrams of the representation of the world.

However, can big data become our new "facts"?

I do not think this is possible because even big data derives from a selection responding to a (subjective) principle of relevance and (in order to be useful and manageable) some small-scale filters that insert specific, focused paths.

The quantity of big data is, in short, never total, and it is a quantity that is always temporary, and, as such, partial.

My impression is that big data solicits a great illusion of objectivity thanks to its impersonality, but as a semiotician knows well, the strategies of quantifica- 
tion, depersonalization, diagrammaticalization, are only enunciative strategies for the construction of meaning effects. We have to take care not to confuse the effect of "objectivity" with the level of primacy and factuality I mentioned earlier as the Dynamic Object, which (I repeat) I believe exists but has very little to do with the objectivity we are appealing to today.

\section{From Truth to Legitimation}

In this two-sided feature of the post-truth regime (with the claim to many truths on one hand, and the claim of impersonal objectivity on the other) the judgement of legitimacy falters: if the possible truths are so many and different, what makes an affirmation on the web legitimate (or illegitimate, or amendable, or sanctionable)?

This is a significant problem at a legal level: can misleading news be legally judicable and sanctionable? Moreover, what kind of evidence does algorithmic or diagrammatic data represent?

In summary, to what extent does the confusion over the category of truth make the concept of judicable and sanctionable also confused?

I believe that rethinking the category of legitimacy is crucial and strategic in order to rethink (replace?) those of truth, correctness, objectivity, and in order to manage the "digital truth regime". ${ }^{4}$ Legitimacy is a useful concept, not only with which to manage the legal problems tied to post-truth and fake-news, but also the problem of truthfulness in post-truth regime in general. After all, we know that the distinction between legality and legitimacy has already been drawn (here I refer to Schmitt [10]), defining the whole distance between a formal criterion and void of content, and a criterion that instead finds its foundation not in form but in an "appropriateness" that has a historical-cultural foundation.

Without entering into a reflection on the philosophy of history and law, the advantage that is offered, in my view, by the concept of legitimacy over that of truth, has to do with the reference to a given context (wherein truth tends to be a universal ideal), with an element of social recognition (wherein truth does not depend on recognition; it is valid per se) and a processual dimension (wherein truth does not become truthful). We could say that legitimacy moves the focus from rigor and correctness (within the field of legality) to adequacy and justification (within the field of historicity).

Legitimacy depends on there being conformity with the law, the rules of the current legislation, but even before this, it depends on a preliminary form of appropriateness that makes the exercise of power adequate. In order to say and fix what is legitimate, you must have the right to do so; your exercise of power has to be recognized. Administratively, for example, a defect of legitimacy can be ascribed to incompetence, to a violation of law or an excess of power.

In short, legitimacy involves:

\footnotetext{
${ }^{4}$ I have found a number of useful reflections on this, in [11-13].
} 
- Norms (cultural norms)

- Rules (legal laws)

- Adequacy and correspondence to the role of exercising power

Nevertheless, we cannot speak of legitimacy without recalling the tripartition that Weber [11] outlines for the possible roots of the legitimation of power: legitimation can be traditional, charismatic, and rational. This distinction is a great stimulus in the current reflection on the truth. I will allow myself to reinterpret it by saying that the truth can find legitimacy in a presumed rational level of correspondentist reality, in reference to the (charismatic) personality of the enunciator, or in reference to the system of beliefs, values, and traditions of any given culture. In each of these cases, there is no question of objectivity, but a question of relationship to. Legitimacy is something that must be recognized in order to be effective. It depends on a kind of interpretation that must recognize the adequacy of a set of rules and of the subject who guarantees these rules. This interpretation can be influenced by tradition, charisma, or rational reason. In any case, it is not a subjective, individual interpretation but something that involves an inter-subjective recognition. A legitimation recognized by just one person would not be a legitimation (maybe it would be just the other side of a "self-assertion" in the sense of Blumenberg [14], not fully realized); a norm that would seem legitimate to just one citizen, a scientist who would be perceived as reliable just by one person, would be cases of personal preferences, personal "passions", not cases of shared valorization. Nothing prevents a scientist from being gradually trusted by more and more people; and, therefore, their position would be legitimized by a social sharing (just as nothing prevents the legitimacy of said scientist from going into crisis, if others were to discover that their positions were indefensible), but this has to do with the procedurality of legitimacy, its being in progress and never definitively stable. Not being an abstract element but a variable function, dependent on subjects, contexts, traditions, and charisma, means legitimacy can always be revised and always needs motivation. It needs a new foundation each time: it never remains a given forever, as truth values instead aspire to be.

In my opinion, it is highly appropriate to reframe the problem of truth in terms of legitimacy for the current regime of post-truth, where we find some very specific features:

- As we know, web 2.0 has cancelled out the difference between content creators and recipients, establishing a circularity in which we are all authors and readers. This circularity has completely, eliminated the possibility of distinguishing subjects appointed to speak, competent and authorized to do so, and subjects authorized only by circumstances. A technical possibility (anyone can be a content author) has become a matter of rights, and so everyone is entitled to become a source of information.

Re-establishing a reflection on competences as the basis of a legitimate right to speak, and not only in terms of technical possibility or legal right to express oneself, would be the principle of an information ecology that would preserve a critical vocation. 
Thinking in terms of legitimacy also coincides with a complex idea of compliance with rules. In other words, it involves the preliminary assumption that there are and must be rules, and that social life is indeed based on certain institutions. But we have to think of discursive rules, rhetorical rules, pragmatic rules of propriety, respect, commitment, transparency, and so on (and not only legal, "formal" rules). Any rule is historical and, therefore, subject to change, but until it is valid, it defines certain boundaries, and what transgresses these boundaries is illegitimate. If we think of the deregulation that has characterized and continues to characterize a thousand online practices today in the digital world, we can guess at how urgent and unapparent this idea is. The right to free speech does not mean the right to say anything without respecting the pragmatic rules (even if they were only those laid out by Grice). Similarly, the democratization of opinions does not mean freedom from any constraint of words: if democracy has its rules in politics, it will also need them in the information universe.

Finally, the criterion of legitimacy highlights a link that the criterion of truth fails to make clear: the indissoluble link between the private dimension and the social dimension.

A judgment of truth usually relates (in common perception) to a state of fact: something corresponds (or not) to the truth. A judgment of legitimacy relates a sentence (albeit personal) to the network of (inter-subjective) rules provided by a system, and to the speaker appointed a voice in any given field. Individual and collective components are always there.

It is not trivial to recall this aspect because in online communication (in online defamation and hate speech, etc.) this border continues to be a problem: is affirming an aggressive content towards a third party a matter of freedom of expression (fundamental right of the person), or a matter of information law (the right to truthful information), and as such of public law?

\section{The Interpretative Dimension}

Thinking about the problem of the truth of discourses in terms of the legitimacy of the statements and legitimacy of the subjects speaking, obviously throws up many questions and demands a radically cultural and interpretative approach for which semiotics could offer a number of tools. I would like to focus in particular on:

- The question of discursive "authorizations". I am not thinking so much about the management of shifts in vocabulary, but about what is allowed to be said and what exceeds the possibility of expression (until some years ago, in Italy at least, blasphemous language was on the margins of the acceptable; we know that in United States there are stops imposed by political correctness; in Muslim (?) countries one cannot say the word "Allah" without following it with the words 'glory to him the exalted'; we regularly measure how certain cartoons printed by Charlie Hebdo transgress the rules of what is speakable, and so on). These rules are almost never written. Rather, they are a matter of cultural competence, and they belong, are clear, only to those who are part of a given culture. Differences 
(in intercultural terms but also in terms of the digital divide) are a problem. Sometimes a discursive act can sound illegitimate simply because of a cultural divide between speaker and addressee. This is not a problem of truth; it is a problem of adequacy to the cultural context, of an interpretative ability to understand the context and what is speakable, and what is not.

- The question of ideological manipulations. Very often, public discourses tend to self-legitimize, responding to the question of legitimacy with an ideological rhetorical strategy. I refer here to Umberto Eco's conception of ideology expressed in $\S 3.9$. of $A$ Theory of Semiotics [15] as concealment of the partiality of a speech. For the most part, self-legitimating discourses are ideological discourses, which through a rhetorical inventio and dispositio (respectively, inventio is the retrieval of the topics, while dispositio is the discursive presentation of these topics) hide the contradictory nature of culture and the other possibilities culture opens up. (So that, just to give an example, in a speech on dietary regimes to promote weight loss through the elimination of carbohydrates, the fact that an excess of animal protein can raise cholesterol is hidden.)

A genuine reflection on the legitimacy of a statement should imply the awareness of its partiality, avoiding any idealistic absolutization (whilst the web today is characterized by a growing and constitutive radicalization that idealizes the impartiality and as such the absolute nature of its statements).

The question of narratives: narratives are mostly used to legitimize statements, to give them a preliminary frame of plausibility. For this reason, in order to evaluate the legitimacy of discourses, it is crucial to identify and analyze the narrative which, like a frame, contains them. Thinking about the truth of statements justifies an atomistic thought: every statement has (or does not have) its truth. Thinking about the legitimacy of statements instead implies a broader look at the network of statements that make it acceptable (or unacceptable), the frames of meaning that justify it.

Obviously, there are some risks: the risk of relativism that seems to be involved in any form of coherentism (every statement can be legitimate in a certain coherent sphere of statements) and the risk of circularity (anything said by legitimate speakers is legitimate).

In this regard, I believe it is fundamental to keep in mind the multidimensionality of the judgment of legitimacy, or its dependence on a network in which the following are at stake:

- Competences to speak (for example: we could all, in terms of abstract potentiality, say anything, about the field of medicine, but not all of us have the certified knowledge to do so)

- Adequacy with respect to the encyclopaedia of one's own culture. As Eco emphasizes in Kant and the Platypus [16], §1.9. when speaking of the most convincing and preferable theories, the point is not the novelty of the theory, but the extent to which the new theory is able to answer the various problems posed by the system, its adequacy to the cultural system in which it resides. A good theory (a legitimate theory) is not solely required to answer a question, but to satisfy the entire system with its requests. 
- Effects in the Short and Long term: I believe that legitimacy should not be commensurate solely with the intentions and the authority of the speaker (sincerity and charisma, we could say), but with the effects that a given discourse produces: both meaning effects and pragmatic effects. After all, Peirce's pragmatic maxim is precisely this: that the sign's meaning lies in the dispositions to act that it produces. We can think of many cases in the field of medicine: what would the effect be if, over a decade, we did not vaccinate children? Or no longer used antibiotics? Given the large-scale effects of these choices, I think that we could agree that certain statements about vaccines are not legitimate, at least until someone can demonstrate that the systematic rejection of vaccines would not increase the mortality rate. There is, of course, a delicate problem here of potential friction between the communitarian regime of legitimacy and the individual space of choice. I believe, however, that the long term, large-scale effects considered by the communitarian regime (as it considers the systematic dimension of statements, their justifications in the system of culture, their effects according to the system of culture) are two crucial dimensions that manage and, within the limits of the case, limit the freedom of choice. We have experienced it, perhaps, more clearly than at other times during the period of the Covid19 pandemic: faced with the shared opinion of scientists to opt for a lockdown, there could be individual choices of non-isolation, affirmations of the freedom of their own movements. But could we have defined this choice legitimate, in light of the consequences (on a scale of weeks and maybe months) in terms of contagion? The logical and empirical possibility of affirming and making choices is evidently different to the legitimacy (by social force) of the choices themselves.

Competences of speakers, adequacy of statements to the whole cultural system, and pragmatic and systematic effects are, in some sense, our guardrail, the limits to our interpretative freedom. ${ }^{5}$ If the judgement of legitimacy implies an interpretative work, this interpretive work is not entirely unbridled. It does not have the guarantee of a strong, abstract, criterion of truth; it cannot consist of an automatic and objective verification, but has the limits of a reasonable work of interpretation. And even with some risks, the paradigm change from truth to legitimacy would help us be less radicalized, more sensitive to cultures different to our own, more respectful of social norms and rules, in a world where the orders of discourses are increasingly confused by technological progress, and deregulation seems to be the Rule.

Acknowledgements Open access funding provided by Alma Mater Studiorum - Università di Bologna within the CRUI-CARE Agreement.

Open Access This article is licensed under a Creative Commons Attribution 4.0 International License, which permits use, sharing, adaptation, distribution and reproduction in any medium or format, as long as you give appropriate credit to the original author(s) and the source, provide a link to the Creative Commons licence, and indicate if changes were made. The images or other third party material in this

\footnotetext{
${ }^{5}$ I make reference here to the same logic as Umberto Eco in The Limits of Interpretation [17] in which - against deconstruction and radical pragmatism — he affirms that we need guardrails, bans to stop us from going beyond certain limits. We cannot fix any mandatory directions, but we can fix some guardrails.
} 
article are included in the article's Creative Commons licence, unless indicated otherwise in a credit line to the material. If material is not included in the article's Creative Commons licence and your intended use is not permitted by statutory regulation or exceeds the permitted use, you will need to obtain permission directly from the copyright holder. To view a copy of this licence, visit http://creativecommons.org/ licenses/by/4.0/.

\section{References}

1. Floridi, Luciano. 2014. The Fourth Revolution: how the Infosphere is Reshaping Human Reality. Oxford: Oxford University Press.

2. Foucault, Michel. 1975. Surveiller et punir. Paris: PUF. Engl. trans. Discipline and Punish. New York: Pantheon Books, 1977.

3. Foucault, Michel. 1976. La fonction politique de l'intellectuel. In Dits et écrits, vol. II: 1976-1988, Paris: Gallimard, 2001: 109-114, Engl trans. The political function of the intellectual, in Radical Philosophy, 17 (Summer 1977): 12-14.

4. Lorusso, Anna Maria. 2018. Postverità. Fra reality tv, social media e storytelling. Roma-Bari: Laterza.

5. Peirce, Charles S. 1931-1935. Collected Papers. Cambridge: Harvard University Press.

6. Marconi, Diego. 2015. Per la verità. Torino: Einaudi.

7. Williams, Bernard. 2002. Truth and Truthfulness: An Essay in Genealogy. Princeton, N.J.: Princeton University Press.

8. Pariser, Eli. 2011. The Filter Bubble. New York: Viking.

9. Grice, Paul. 1991. Logic and Conversation, 20-40. Cambridge (Mass): Harvard University Press.

10. Schmitt, Carl. 1932. Legality and Legitimacy. Translated and edited by Jeffrey Seitzer with an introduction by John P. McCormick. Durham: Duke University Press, 2004.

11. Weber, Max. 1992. Wirtschaft und Gesellshaft. Tübingen. Engl. Trans. Economy and Society. Berkeley: University of California Press. 1978.

12. Flathman, Richard E. 2017. Legitimacy. In A Companion to Contemporary Political Philosophy, ed. Robert E. Goodin, Philip Pettit, and Thomas Pogge, 2017. New York: Blackwell.

13. Pakulski, Jan. 1986. Legitimacy and Mass Compliance: Reflections on Max Weber and Soviet-Type Societies. In British Journal of Political Science, Vol. 16, No. 1 (Jan., 1986), 35-56. Camridge: Cambridge University Press.

14. Blumenberg, Hans- Schmitt, Carl. 1971-1978. Briefwechsel 1971-1978. Frankfurt: Suhrkhamp.

15. Eco, Umberto. 1976. A Theory of Semiotics. Bloomington: Indiana U.P.

16. Eco, Umberto. 1997. Kant e l'ornitorinco. Milano: Bompiani. Engl.Trans. Kant and the Platypus. New York: Harcourt. 1999.

17. Eco, Umberto. 1990. I limiti dell'interpretazione. Milano: Bompiani. Engl. Trans. The Limits of Interpretation. Bloomington: Indiana U.P. 1990.

Publisher's Note Springer Nature remains neutral with regard to jurisdictional claims in published maps and institutional affiliations. 